Discussion Paper No. 03-61

\title{
The Kyoto Protocol:
}

A Review and Perspectives

Christoph Böhringer

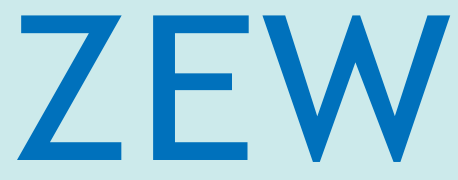

Zentrum für Europäische Wirtschaftsforschung $\mathrm{GmbH}$

Centre for European

Economic Research 
Discussion Paper No. 03-61

\title{
The Kyoto Protocol: \\ A Review and Perspectives
}

\author{
Christoph Böhringer
}

Download this ZEW Discussion Paper from our ftp server:

\section{ftp://ftp.zew.de/pub/zew-docs/dp/dp0361.pdf}

Die Discussion Papers dienen einer möglichst schnellen Verbreitung von neueren Forschungsarbeiten des ZEW. Die Beiträge liegen in alleiniger Verantwortung der Autoren und stellen nicht notwendigerweise die Meinung des ZEW dar.

Discussion Papers are intended to make results of ZEW research promptly available to other economists in order to encourage discussion and suggestions for revisions. The authors are solely responsible for the contents which do not necessarily represent the opinion of the ZEW. 


\section{Non-Technical Summary}

More than 10 years of climate policy negotiations have produced the Kyoto Protocol, the first legally binding international agreement on climate protection, which may enter into force in the near future.

Opponents to the Protocol have condemned it as a "deeply flawed agreement that manages to be both economically inefficient and politically impractical" (McKibbin and Wilcoxen 2002, p.107). This article sustains a more positive perspective on the Kyoto architecture. Key elements of the Protocol comply with basic economic principles. The Protocol is based on a control mechanism that allows iterative adjustment and movement toward evolving goals. A system of periodically negotiated five-year periods supports a flexible approach that allows policy-makers to adjust their decisions according to better information obtained in the future. The Protocol constitutes the first international environmental agreement that builds on market based instruments to determine cost-efficient responses to the undisputed need for GHG abatement. Last but not least, Kyoto - after tough bargaining - came up with a burden-sharing scheme for the first commitment period that all major Parties (with exception of the US) have accepted as a "fair" compromise, hereby reflecting historic responsibilities for the greenhouse gas externality as well as ability to pay.

On the other hand, it must be clearly stated that the Kyoto Protocol - as it stands now - has not achieved a decisive breakthrough in international climate policy. First, sink credits, hot air through emissions trading and, in particular, U.S. repudiation will make Kyoto ineffective in environmental terms during the first commitment period. Second, it has yet to be negotiated what must be done after the first commitment period.

The major challenge for future Post-Kyoto climate policies remains as to how international cooperation on the provision of climate protection (as a global public good) can be promoted. In the first place, this requires incentives for developing countries to participate. Ultimately, this comes down to how abatement duties - or emission entitlements - should be allocated across countries over a longer time horizon. In the second place, a credible system of direct or indirect sanctions must be developed that can deter free-riding. 


\title{
THE KYOTO PROTOCOL:
}

\section{A REVIEW AND PERSPECTIVES}

\author{
Christoph Böhringer \\ Centre for European Economic Research (ZEW), Mannheim
}

\begin{abstract}
International concern about climate change has led to the Kyoto Protocol, negotiated in 1997, which contains legally binding emission targets for industrialized countries to be achieved during the commitment period 2008-2012. While proponents of the Protocol celebrate it as a breakthrough in international climate policy, opponents criticize that its approach, namely setting targets and timetables for emission reductions, is seriously flawed. This paper provides a critical assessment of the Protocol's potential performance and discusses amendments to foster its effectiveness and efficiency. It concludes that, even without any effective emission reductions in the initial commitment period, the ratification of Kyoto is important for the further policy process of climate protection. The Kyoto Protocol has established a flexible broad-based international mechanism that provides a valuable starting point for shaping efficient climate policies in the future.
\end{abstract}

Keywords: climate policy, cost-benefit analysis, Kyoto Protocol,

JEL: D61, H41, Q25

\section{Acknowledgements}

I am grateful to Andreas Lange, Andreas Löschel, David Pearce, and two anonymous referees for helpful comments. Regarding any remaining inadequacies, the usual caveat applies. 


\section{Introduction}

Climate change caused by anthropogenic greenhouse gases has emerged as one of the most important environmental issues facing the international community. Greenhouse gases particularly fossil fuel-based carbon dioxide emissions - are accumulating in the atmosphere as a result of human activities, and the ongoing increase in greenhouse gas concentrations is expected to raise the global average temperature and cause other changes to the climate.

International concern about climate change has led to the Kyoto Protocol in 1997 which contains legally binding emission targets for industrialized countries to be achieved during 2008-2012 (the so-called Kyoto commitment period). The proponents of the Protocol celebrated it as a breakthrough in international climate policy, because (i) it promised - under the original provisions - substantial emission reductions for the developed world vis-à-vis business-as-usual emissions, and (ii) it established a broad international mechanism for widening and deepening climate protection activities in the future. Opponents to the Protocol rejected it as a "deeply flawed agreement that manages to be both economically inefficient and politically impractical" (McKibbin and Wilcoxen 2002, p.107). In fact, after years of tedious negotiations on its concrete implementation, the Protocol has yet to enter into force, waiting for Russia to translate its positive public announcements into legal ratification. Moreover, the U.S. refusal to ratify the Protocol and the full tradability of emission entitlements conceded to the former Eastern Bloc in excess of its anticipated future businessas-usual emissions (so-called hot air) imply that the current round of the Kyoto Protocol is likely to accomplish very little in terms of global emission reductions (see Buchner et al. (2002) or Springer (2002) for surveys of Kyoto assessment studies). This evolution seems to confirm the position of the Protocol's antagonists that its fundamental approach - setting targets and timetables for emission reductions - is seriously flawed.

Against this background, I want to provide a critical assessment of the Protocol's anticipated performance and discuss potential amendments to foster effectiveness and efficiency in subsequent commitment periods. In section II, I briefly summarize the economic characteristics of climate protection as a global public good and derive key criteria for the design of appropriate climate policy regimes. In section III, I lay out the provisions of the Kyoto Protocol as it is most likely to enter into force (if at all) and provide an assessment of the associated economic and environmental impacts. In section IV, I measure the fundamental 
approach underlying the Kyoto Protocol against key criteria of a meaningful climate policy architecture and suggest amendments that might improve on the Protocol's performance in Post-Kyoto commitment periods. In section V, I present conclusions.

\section{Climate Protection -The Key Issues}

Rational decision-making in climate policy requires balancing the cost of greenhouse gas emission abatement and the benefits of avoided undesirable consequences of global warming. Classical cost-benefit analysis (see e.g. Mishan 1975 or Pearce 1998) provides the appropriate framework for measuring all negative and positive policy impacts and resource uses in the form of monetary costs and benefits. An emission mitigation policy that allocates society's resources efficiently maximizes net benefits: Emissions reduction efforts are taken up to the level where the marginal benefit equals the marginal cost.

Combating global warming constitutes the problem of providing a global public good. Public goods are commodities for which the cost of extending the service to an additional individual is zero and for which it is impossible (or expensive) to exclude individuals from enjoying it. These features of non-rivalry and non-excludability apply to climate protection.

A first-best, i.e. globally efficient, response policy to climate change requires an international environmental policy which takes into account the benefits for all countries that emission abatement in a single country produces. Given complete information, a global cost-benefit analysis could tell us how much greenhouse gas (GHG) emissions should be abated, when and by whom. However, at a decentralized level, individual rational countries only pursue their own interests and neglect the positive externalities of their reduction measures for other countries. Thus, the level of GHG emission reductions will be too low.

Table 1, together with Figure 1, illustrates the potential gains from global cooperation in a simple, stylized framework. In the first-best (global) optimum, marginal costs of abatement in one country equal the sum of marginal benefits across all countries. Moreover, marginal abatement costs are equalized across sources - abatement is undertaken where it is cheapest (so-called "where"-flexibility). Generally, efficiency also requires equalization of marginal abatement costs across time with appropriate discounting (so-called "when"-flexibility). This 
is because the effect of GHG emissions on global warming depends on the cumulative emissions in the atmosphere. The stock nature of climate change implies that policies can take a wide range of emission paths over the next decades to achieve the same atmospheric concentrations of greenhouse gases (Wigley et al. 1996).

Table 1: Non-cooperative versus cooperative approach in GHG abatement

$i(j)$ : country index; $C_{i}$ : costs; $B_{i}$ : benefits; $x_{i}$ : abatement; $X=\sum_{i} x_{i}:$ global abatement

\begin{tabular}{|c|c|}
\hline Non-cooperative solutior & Cooperative solution \\
\hline \multicolumn{2}{|c|}{ Optimization problem } \\
\hline $\max _{x_{i}} B_{i}(X)-C_{i}\left(x_{i}\right)$ & $\max _{x_{i}} \sum_{j}\left[B_{j}(X)-C_{j}\left(x_{j}\right)\right.$ \\
\hline \multicolumn{2}{|c|}{ First-order conditions } \\
\hline$C_{i}^{\prime}=B_{i}^{\prime}$ & $C_{i}^{\prime}=\sum_{j} B_{j}^{\prime}$ \\
\hline
\end{tabular}

Figure 1: Efficiency gains from cooperation

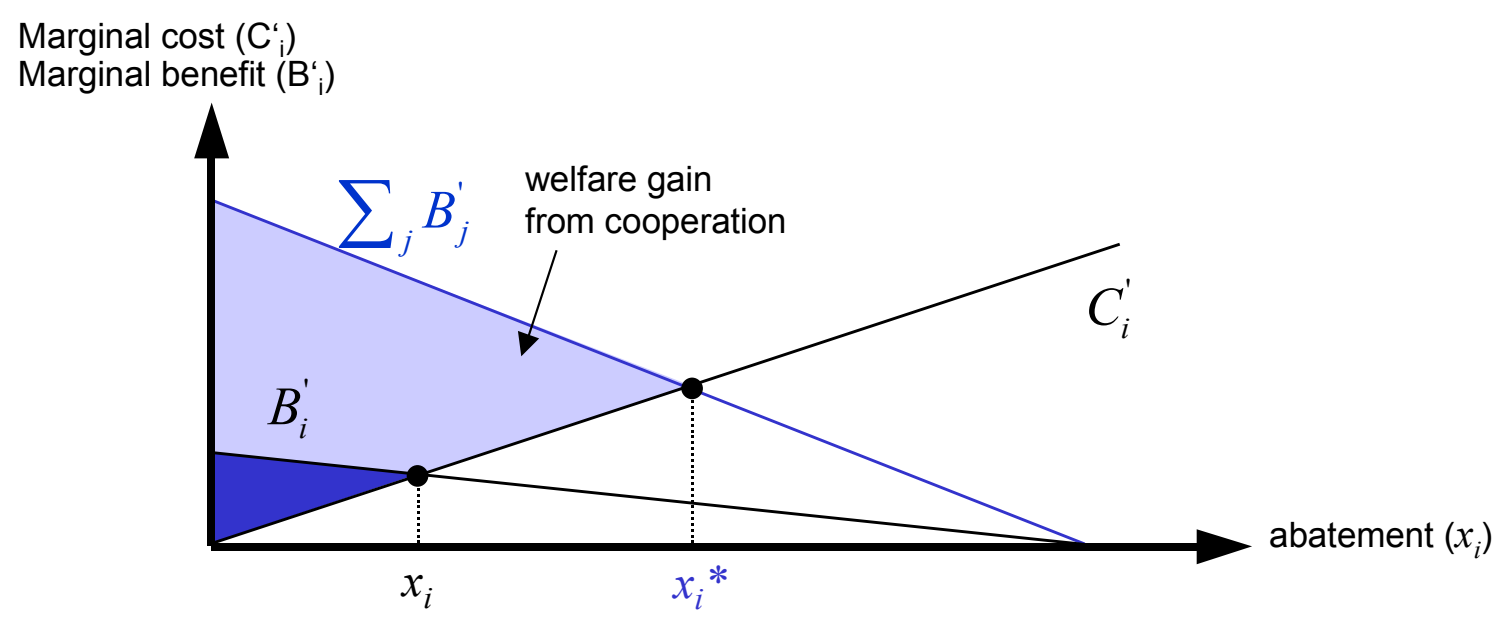

At first glance, the optimal solution to the GHG problem seems straightforward. But a closer look reveals severe obstacles. First, large uncertainties on the cost and benefit of GHG abatement render decision-making in climate policy very difficult. Second, there are, at best, only weak economic and political mechanisms to enforce cooperative behavior between sovereign countries. 


\section{(i) Uncertainty}

The first-best solution to climate change requires concrete information, not only about the cost, but also about the benefits of abatement. However, the chain of causality - from GHG emissions to ambient concentrations of greenhouse gases in the atmosphere, from temperature increase to physical effects such as climatic and sea level changes - is very complex and hardly understood. Moreover, economists do not even agree on the methodology to be used for valuing certain potential climate change impacts such as the extinction of a species. The large uncertainties in predicting global climate change, as well as quantifying and monetizing the associated biophysical impacts, explain much of the controversy on the desirable longterm level of greenhouse gas concentrations in the atmosphere and the scope and timing of emission mitigation measures.

The uncertainties, together with (partial) irreversibility of both GHG accumulation in the atmosphere and accumulation of capital investments, imply a trade-off between the risk of premature abatement action and the risk of delayed action. In the context of uncertainty, option theory typically replaces classical cost-benefit analysis in evaluating decisions (see e.g. Arrow and Fisher 1974, Hanemann 1989, Dixit and Pindyck 1994). The relative irreversibility between climate change and mitigation measures (including adaptation) will determine which option - whether to wait until more information is available, or to invest now - is more valuable. In practice, this leads to a sequential decision-making approach that is sufficiently flexible to incorporate new information.

Given the large uncertainties, the international community's primary climate policy objective - as adopted in the United Nations Framework Convention on Climate Change (UNFCCC 1992) - has not been the balancing of benefits and costs based on an elaborate option value approach. In a situation subject to tremendous uncertainty, alternative options become rather incommensurate. Presuming that uncertain future outcomes of climate change could be extreme and irreversible, risk aversion suggests the adoption of the precautionary principle. ${ }^{1}$

In this vein, the UNFCCC aims at establishing an ample margin of safety based on recommendations from natural science on "tolerable" emission levels. The UNFCCC's stated

\footnotetext{
${ }^{1}$ Gollier et al. (2000) identify conditions such that scientific uncertainties justify immediate prevention measures. They also mention the precautionary principle as a safe-guard against the opportunism of decision-makers in situations of asymmetric information or imperfect societal monitoring.
} 
goal is the "stabilization of greenhouse gas concentrations in the atmosphere at a level that would prevent dangerous anthropogenic interference with the climate system" (UNFCCC 1992, Article 2). As pointed out by the Intergovernmental Panel on Climate Change (IPCC), which serves as the scientific advisory board to the UNFCCC, stabilizing concentrations at "safe" levels may require reductions of much more than 50\% below current levels in 2100 (IPCC 2001). After choosing some desirable global emission trajectory, cost-effectiveness analysis as a second- or third-best policy approach then minimizes aggregate costs of abatement for the given - typically sub-optimal - global emission target. ${ }^{2}$

Apart from the problems of identifying optimal abatement trajectories, uncertainty may have important implications for the choice of the regulatory instrument. Under uncertainties for damages and abatement cost estimates, price instruments (such as a harmonized GHG tax) and quantity instruments (such as tradable GHG emission rights) that can both assure equalization of marginal abatement costs are no longer equivalent in cost-efficiency terms. Under a quantitative limit, marginal costs are uncertain; under a fixed tax, emission reductions are uncertain. Weitzman (1974) showed that the tax is superior if the marginal cost curve is steep relative to the marginal benefit curve (and vice versa). Several economists have used the Weitzman argument to make a strong case that GHG taxes are likely to be more efficient than tradable permits. The underlying presumption is that "all evidence to date suggests that the marginal cost curve for reducing GHG emissions is very steep .... [whereas] ... the [stock] nature of climate change indicates that the marginal benefit curve for reducing emissions will be very flat." (McKibbin and Wilcoxen 2002, p.118). However, the presumption of a rather linear marginal damage function need not accurately reflect the expectations of most scientists about larger non-linearities in the climate system (e.g. Higgins et al. 2002) and warrants caution with a rather simplistic and too definitive siding with the price instrument. Incorporating uncertainty, Roberts and Spence (1976) demonstrate that the combination of a quantity instrument with a price instrument can efficiently protect against the failings of each single instrument. Applied to climate change policies, this means that a mixed system is likely to do better than either a fixed quantity or a pure tax. More specifically, a finite penalty can provide an "escape valve" under a quantity regime in case abatement costs turn out to be very high.

\footnotetext{
${ }^{2}$ Note that cost-effectiveness assures only a least-cost way of doing "something" that still might be fundamentally unreasonable in economic terms.
} 


\section{(ii) Incentive Problems}

There are fundamental problems to achieve first-best or second-best response policies to global warming within an international environmental agreement (IEA). The main problem is the lack of a supranational authority that could coerce countries into the implementation of globally efficient climate policies. ${ }^{3}$ In other words, the provisions of GHG abatement must be voluntary, i.e. an IEA should be self-enforcing. The main challenge to climate policy is thus to shape international agreements that create incentives for sovereign states to enter cooperation. Principal guidelines may come from coalition theory, a field of game theory that analyzes the incentive structures of countries to participate in an IEA and to comply with the terms of the agreement (for non-technical overviews see e.g. Carraro and Siniscalco 1998 or Finus 2003).

A first prerequisite for a self-enforcing IEA is that countries must be better off with the IEA than they would be with the non-cooperative status quo. Often, transfers might be necessary to meet this condition. In the climate policy negotiations on the allocation of abatement duties across countries, the issue of transfers is implicit to the assignment of emission entitlements. ${ }^{4}$ However, the question of how efficiency gains from cooperation should be "fairly" allocated across countries ultimately remains a normative issue (see e.g. Moulin 1990, 1991 or Böhringer and Helm 2001) that is fundamental to climate change policies. It may not only be necessary that all countries are better off from cooperation than in the non-cooperative situation, but also that the distribution of the gains from cooperation comply to "acceptable" equity principles.

Second, even in the case of profitability, there are severe free-rider incentives either to remain a non-signatory to the $\operatorname{IEA}^{5}$ or to participate in the IEA but violate its terms. The rationale

\footnotetext{
${ }^{3}$ This includes the imposition of fairness principles about how gains from cooperation should be shared.

4 In formal terms, the optimization calculus of the individual country becomes $\max _{x_{i}} B_{i}\left(\sum_{j} x_{j}\right)-C_{i}\left(x_{i}\right)-p\left(x_{i}-\bar{x}_{i}\right)$, where $\mathrm{p}$ denotes the global shadow price per unit of emission abatement and $\bar{x}_{i}$ is the initial assignment of (tradable) abatement duties $\left(\sum_{j} x_{j}=\sum_{j} \bar{x}_{j}\right)$. Neglecting income effects, the mode of allocating abatement duties has no effect on global efficiency: in the global planning problem, the term $\sum_{j}\left(x_{j}-\bar{x}_{j}\right)$ cancels out.

${ }^{5}$ Generally, this covers the case of a coalition that contributes less to abatement than other coalitions.
} 
behind free-riding is to save abatement costs while benefiting from abatement efforts of other countries. This leads to the well-known "tragedy of the commons": Although all countries could be better off if they behaved in a cooperative way, each one has an incentive to deviate from the Pareto-efficient outcome. Paradoxically, the free-rider incentives of nonparticipation and non-compliance are particularly strong for conditions under which cooperation would generate large global welfare gains as is the case for global warming (Barrett 1994, Carraro and Siniscalco 1993). On the one hand, the global character of the GHG externality provides large gains vis-à-vis the non-cooperative solution. On the other hand, the large number of countries affected by GHG emissions increases the free-rider incentive from the single-country perspective: Environmental quality will deteriorate only marginally if the single country defects from the IEA, whereas participation and compliance may impose substantial costs with only marginal improvements in environmental quality. Similarly, the high degree of asymmetry between countries with respect to costs and benefits of emission abatement promises large gains from cooperation, but, at the same time, poses problems for participation and compliance: Countries that benefit less from cooperation have an incentive to either remain non-signatory or violate the terms of agreement (Botteon and Carraro, 1993).

Credible sanctions are necessary, if free-rider incentives are to be reduced. "Credible" implies that countries carrying out the punishment should not suffer a disadvantage (as might be the case for instance with trade embargoes). Furthermore, the violator should have an incentive to "accept" the sanction, given the fact that sovereign signatories typically can leave an IEA to avoid punishment. In technical terms: credible sanctions must be renegotiation-proof. One sanctioning option frequently mentioned in the literature is issue linkage, consisting in the exchange of concessions across different policy dimensions. The incentive for countries to contribute to pollution abatement can be increased via the threat that if they do not join the linked agreement, they will also not enjoy the benefits of another agreement such as R\&D cooperation or trade treaties. Typically, proposals for issue linkage include club-good agreements in which the gains from cooperation are exclusive to signatories, making freeriding of minor importance. Issue linkage, thus, boils down to reducing the pure public good character of GHG abatement, thereby lowering free-rider incentives. In policy practice, however, such sanctions might be in conflict with concurrent legislation, e.g. WTO regulations. Other, more explicit sanctions include penalty payments to violators, and reciprocal behavior, i.e. a reduction of abatement efforts of other participants (Finus 2003). 
Beyond the fundamental incentive problems of international cooperation, climate change policy has an important political economy dimension (Congleton 1992, 2001): Governments may not maximize the welfare of their citizens but the probability of being re-elected. From a political economy point of view, the median voter's willingness to pay ultimately determines the outcome of international environmental negotiations. If voters are myopic and discount much time, the incentives for joining an IEA on GHG emission abatement may decline substantially. The reason is that major GHG gases, such as $\mathrm{CO}_{2}$, are stock pollutants that remain in the atmosphere for several decades before they disappear due to the natural rate of decay. Therefore, short-term abatement efforts will have an immediate impact on abatement costs, but generate only far-distant benefits.

\section{(iii) Guidelines for Practical Climate Policy Design}

There is widespread consensus that climate change represents a significant potential threat requiring the reduction of man-made GHG emissions from current and expected future Business-as-usual emissions. However, the substantial uncertainties in estimating costs and benefits from GHG abatement make the question of the "right" or the "optimal" level one of the most difficult and controversial issues in the economics of climate change. Furthermore, given the public good character of the global atmosphere and the inherent free-riding incentives, greenhouse gas reduction cannot be achieved without international cooperation that is codified in a long-term international policy agreement. Reaching such an agreement is only likely when the international parties perceive the distribution of costs and benefits as fair (see e.g. Morrisette and Plantinga 1991, Bohm and Larsen 1994). In other words, fairness "serves a positive role as a unifying principle that facilitates an international greenhouse warming agreement" (Rose et al. 1998). Efficiency and equity are, therefore, two intertwined fundamental principles that must be addressed together in the design of climate policies.

Against this background, a generic - admittedly simplistic - approach to climate policy could be composed of four steps that would be iterated in a sequential decision process to incorporate new information.

The first step is that, until more certain scientific information on climate change is available, climate policy adopts a precautionary approach with respect to long-term stabilization targets. Keeping in mind that the stabilization issue is a GHG budget allocation problem, many 
different pathways exist to achieve the same stabilization target. Conventional costeffectiveness considerations would suggest rather low near-term reductions and offsetting high long-term reductions because (i) technological development will probably deliver cheaper low carbon technologies in the future, (ii) reallocation of the current capital stock may cause large adjustment costs, and (iii) a positive rate of interest implies that the present value of an economic burden to current generations gets smaller the further out in the future the burden lies. ${ }^{6}$ Yet, these arguments should not be construed in favor of a blunt "do nothing" or "wait and see" policy. There is substantial inertia of economic systems that produce GHG emissions. This implies transition costs for switching from one emission path to another. Accounting for uncertainty about the long-term optimal concentration ceiling, the socioeconomic inertia suggests that "delay in abatement efforts may prove costly" (Ha-Duong et al. 1997).

In a second step, the implementation rules of emission abatement should comply to basic efficiency criteria. Most importantly, this includes the harmonization of marginal abatement costs across space through the use of market-based instruments. Efficiency with respect to the global GHG externality requires broad participation, which in turn depends on profitability and fairness.

Third, climate policy must satisfy distributional concerns that have already dominated previous climate change policy. This involves (complex) negotiations on alternative value judgements, including competing equity criteria, such as responsibility (in terms of the contribution to the GHG problem), ability-to-pay (wealthier nations should lead the response), and the distribution of benefits.

Fourth, credible sanctions must be established to deter free-riding.

\section{The Kyoto Protocol: A Review}

In view of the fundamental problems outlined above, any international agreement on GHG abatement that incorporates basic economic principles of economic decision-making under

\footnotetext{
${ }^{6}$ It should be noted that the cost-effectiveness approach to meeting a given concentration target neglects potentially important differences on environmental benefits across alternative emission paths (see Wigley et al. 1996).
} 
uncertainty while achieving global emissions below the projected business-as-usual level ${ }^{7}$ could be considered a success. Various climate policy makers share this view with respect to the Kyoto Protocol, which - since its signature in 1997 - has been widely celebrated as a milestone towards mitigating global warming. On the other hand, opponents to the Protocol criticize its fundamental approach, saying that "setting targets and timetables for emission reductions, is seriously flawed" (McKibbin and Wilcoxen 2002, p.125). In this section, I will summarize the economic and environmental impacts that Kyoto is likely to bring about during the first commitment period (if it comes into force).

The Climate Change Convention that was adopted during the Rio Earth Summit in 1992 provides the institutional framework for international climate policy. It has been ratified by the vast majority of the world's states. ${ }^{8}$ Periodic meetings of these Parties to the Climate Change Convention - the so-called Conferences of Parties (COP) - should promote and review efforts to combat global warming.

The Kyoto Protocol was negotiated in 1997 during the Third Conference of the Parties (COP3) to the United Nations Framework Convention of Climate Change. It requires industrialized countries - as listed in its Annex B - to limit their emissions of greenhouse gases, most notably $\mathrm{CO}_{2}$ from fossil fuel combustion. More specifically, Annex B countries committed themselves to reducing their GHG emissions by $5.2 \%$ on average below aggregate 1990 emission levels during the commitment period 2008-2012 (UNFCCC 1997). The agreement will not enter into force, however, until two conditions are fulfilled (so-called double-trigger): Firstly, at least 55 Parties to the Convention must ratify the treaty by their national parliaments. Secondly, industrialized countries among ratifying Parties must account for at least $55 \%$ of the total $1990 \mathrm{CO}_{2}$ emissions from this group.

The Kyoto conference in 1997 left open several controversial aspects of concrete implementation, especially with respect to credits for carbon sinks, i.e. forests and agricultural soils that store $\mathrm{CO}_{2}$, and the question of full versus restricted tradability of emission rights across Annex B countries. In March 2001, the U.S. under President Bush explicitly declined

\footnotetext{
${ }^{7}$ Given that benefits from GHG abatement will not unfold until far in the future, it seems reasonable to approximate the non-cooperative solution with the business-as-usual development.

${ }^{8}$ As of mid 2003, the UNFCCC has 187 parties, more than any other international environmental agreement (Barrett, 2003).
} 
to ratify the Protocol, reasoning that the costs to the U.S. economy would be too high and exemption of developing countries from binding emission targets would not be acceptable.' On the subsequent Conference of Parties at Bonn in July 2001, delegates from 180 countries came together, most of them determined to rescue the Kyoto global warming treaty from collapse. The negotiating parties achieved a compromise on the open implementation issues. Australia, Canada, New Zealand, Japan, and Russia were allowed a substantial credit for carbon dioxide sinks, namely forests and agricultural soils that store this greenhouse gas. Moreover, the EU, which hitherto strongly pursued the suppression of "paper" trade in hot air, gave up its restrictive position with respect to the permissible scope of emissions trading between industrialized countries. The latest version of the Kyoto Protocol does not foresee any concrete caps on the share of emissions reductions a country can meet through the purchase of permits from other industrialized countries, nor does it envision a cap on the amount of permits it can sell. In practice, this means that Russia, the Ukraine and Eastern Europe will be able to sell all their surplus emission permits - generally referred to as hot air which may significantly increase the effective emissions under the Kyoto Protocol as compared to strictly domestic action. COP7 in Marrakech (November 2001) confirmed the outcome of Bonn and clarified technical and legal details in the implementation of emissions trading (e.g. monitoring and verification) as well as concrete sanction mechanisms in the case of non-compliance. By mid 2003, entering into force of the Kyoto Protocol depends only on the final ratification by Russia.

Table 2 summarizes the potential environmental effectiveness of the Kyoto Protocol at different stages of the negotiation process for major Annex B country groups. The reduction targets as originally foreseen by the Protocol are reported in the column labeled "Kyoto Targets - OLD". The column "Kyoto Targets - NEW" accounts for the softening of targets through credits for carbon dioxide sinks as agreed upon during the Sixth and Seventh Conferences of the Parties at Bonn and Marrakech (see Nemry 2001). ${ }^{10}$ The reduction targets

\footnotetext{
9 In 1997, the U.S. Senate unanimously passed the Byrd-Hagel resolution, which makes "meaningful" participation of developing countries a conditio sine qua non for ratification (The Byrd-Hagel Resolution, U.S. Senate, 12 June 1997, 105th Congress, 1st Session, Senate Resolution 98). Given that U.S. ratification requires a $2 / 3$ majority in the Senate, the prospects for ratification have been rather small over the years, irrespective of the latest move under the Bush administration.

${ }^{10}$ Since credible data to measure effective sinks from forest management and agricultural activities vis-à-vis the business-as-usual is missing, sink credits under the Kyoto Protocol largely come down to "creative accounting".
} 
with respect to 1990 apply to historic emission levels. Since these targets will not become legally binding before the Kyoto commitment period between 2008-2012, the appropriate reference for the effective cutback requirements are the business-as-usual $(B a U)$ emissions during the commitment period. The column labeled "Baseline Emissions - 2010" reports the projected $B a U$ emissions for the central year 2010 of the commitment period based on the reference scenario of the most recent International Energy Outlook (IEO 2001) by the U.S. Department of Energy.

Table 2: Baseline emissions and emission reduction targets for Annex B regions ${ }^{*}$

\begin{tabular}{|c|c|c|c|c|c|c|c|c|}
\hline \multirow[t]{2}{*}{ Region } & \multicolumn{2}{|c|}{$\begin{array}{l}\text { Baseline Emissions } \\
(\mathrm{MtC})^{\mathrm{a}}\end{array}$} & \multicolumn{2}{|c|}{$\begin{array}{c}\text { Kyoto Targets } \\
(\% \text { vis-à-vis 1990) }\end{array}$} & \multicolumn{2}{|c|}{$\begin{array}{l}\text { Effective Targets } \\
\text { (\%vis-à-vis 2010) }\end{array}$} & \multicolumn{2}{|c|}{$\begin{array}{l}\text { Effective Targets } \\
\text { (MtC) }\end{array}$} \\
\hline & 1990 & 2010 & $O L D$ & $N E W$ & $O L D$ & $N E W$ & $O L D$ & $N E W$ \\
\hline AUN & 88 & 130 & +6.8 & +10.2 & -27.7 & -25.4 & -36 & -33 \\
\hline CAN & 127 & 165 & -6.0 & +7.9 & -27.7 & -17.0 & -46 & -28 \\
\hline EUR & 929 & 1041 & -7.8 & -5.2 & -17.7 & -15.4 & -184 & -160 \\
\hline JPN & 269 & 331 & -6.0 & -0.8 & -23.6 & -19.4 & -78 & -64 \\
\hline CEA & 301 & 227 & -7.1 & -3.9 & +23.2 & +27.5 & +53 & +62 \\
\hline FSU & 1036 & 713 & 0.0 & +6.4 & +45.3 & +54.6 & +323 & +389 \\
\hline Total US out ${ }^{\mathrm{c}}$ & 2750 & 2607 & -5.0 & -0.5 & +0.7 & +3.8 & +32 & +166 \\
\hline USA & 1347 & 1809 & -7.0 & -3.2 & -30.8 & -27.9 & -556 & -505 \\
\hline Total US in ${ }^{\mathrm{d}}$ & 4097 & 4416 & -5.0 & -0.5 & -11.9 & -7.7 & -525 & -339 \\
\hline
\end{tabular}

* For reasons of data availability, we apply the greenhouse gas reduction targets to $\mathrm{CO}_{2}$ only, which is by far the most important greenhouse gas among industrialized countries.

Key: AUN - Australia and New Zealand, CAN - Canada, EUR - OECD Europe (incl. EFTA), JPN - Japan, CEA - Central and Eastern Europe, FSU - Former Soviet Union (incl. Ukraine).

${ }^{\mathrm{a}}$ Based on IEO (2001): reference case $\quad{ }^{\mathrm{b}}$ Estimates by the European Commission (Nemry 2001)

c Annex B without U.S. compliance (assuming full trade in "hot air")

dAnnex B with U.S. compliance (assuming full trade in "hot air")

Except for the economies in transition, which include Central and Eastern Europe (CEA) as well as the Former Soviet Union (FSU), the Kyoto targets with respect to 1990 translate into much more stringent effective targets with respect to 2010, since industrialized countries are projected to have economic growth accompanied by a considerable increase in greenhouse gas emissions from fossil fuel combustion. Australia and New Zealand (AUN), for example, receive emission rights that are $6.8 \%$ higher than their 1990 reference emission levels, but in 2010 they will nevertheless face an effective cutback requirement of $27.7 \%$ vis-à-vis their projected $B a U$ emissions. Apparently, the economies in transition have been endowed with emission entitlements under the Kyoto Protocol that are well in excess of their anticipated 
future $\mathrm{BaU}$ emissions. The final column in Table 2 converts the effective targets from percentage terms into absolute units.

An assessment of Table 2 with respect to the implementation of the Kyoto Protocol in its original form (i.e. U.S. compliance and $O L D$ targets) indicates that the Kyoto Protocol demands a substantial cutback of $B a U$ emissions in the industrialized world. Even in the case of unrestricted Annex B trade in emission rights, which would allow for the full availability of "hot air" from CEA and FSU, aggregate Annex B emissions are supposed to fall by roughly $12 \%$ as compared to $\mathrm{BaU}$ in 2010 (see the intersection of row "Total US in" with column "Effective Targets - OLD"). The row "Total US out" illustrates the dramatic implications of U.S. non-ratification and unrestricted (competitive) permit trade. The total amount of "hot air" exceeds the cumulative cutback requirements across remaining Annex B countries. As a consequence, the Kyoto Protocol boils down to business-as-usual without compliance costs and emission reduction.

The simple story behind Table 2 supports the pessimistic predictions of standard economic theory on the missing prospects for effective and efficient international environmental cooperation. Much more sophisticated analyses that accounts for rationing of "hot air" within a multi-sector, multi-region computable general equilibrium model of global trade and energy use derive qualitatively the same conclusion (Böhringer 2002, Böhringer and Vogt 2003a): Compliance costs and environmental effects under the Kyoto Protocol are rather negligible. Even for extreme assumptions on market power, Kyoto is not much different from Businessas-usual (see also Buchner et al. 2002).

This result fits into the literature on the effectiveness of international environmental agreements such as the Montreal Protocol on chlorofluorocarbon emission reduction or the Oslo and Helsinki Protocols on sulfur emission reduction. Empirical evidence casts serious doubts as to whether such treaties go much beyond the status without any agreement (Murdoch and Sandler 1997a,b and Finus and Tjøtta 2002).

Böhringer and Vogt (2003b) provide a political economy perspective on the Kyoto process. They argue that non-ratification of the Kyoto Protocol by the U.S. is straightforward, given the potential compliance costs and the domestic voters' low willingness to pay. U.S. repudiation of the Kyoto Protocol provided the remaining non-EU Parties to the Kyoto 
Protocol (Canada, Australia, New Zealand, Japan, and Russia) with veto bargaining power. Reflecting the domestic political environment with relatively small willingness to pay, these Parties bargained for far-reaching concessions from the EU on sink credits and, in particular, on the tradability of hot air, boiling the Protocol down to symbolic policy.

\section{The Kyoto Protocol: Perspectives}

Antagonists of the Kyoto Protocol see its failure in terms of environmental effectiveness as a natural consequence of a flawed architecture." All in all, they conclude "that the Kyoto Protocol is an impractical policy focused on achieving an unrealistic and inappropriate goal" (McKibbin and Wilcoxen 2002, p.127). An incomplete list of key arguments against the Kyoto structure follows: (i) "Kyoto does not deter free-riding and non-compliance" (Barrett 1998, p.38); (ii) “The Kyoto Protocol is defective on both efficiency criteria [spatial and temporal equalization of abatement costs] because it omits a substantial fraction of emissions (thus failing the spatial criterion) and has no plans beyond the first period (thus not attending to the temporal dimension)" (Nordhaus 2001, p.8); (iii) "The Kyoto Protocol has an arbitrary allocation of transfers... moreover, since developing countries are omitted, they are completely overlooked in the transfers" (Nordhaus 2001, p.9); (iv) "The most fundamental defect of the Kyoto Protocol is that the policy lacks any connection to ultimate economic or environmental policy objective" (Nordhaus 2001, p.13); (v) "International permit trading [as the principal policy instrument of the Kyoto Protocol] runs the risk of being highly inefficient, given uncertainties in the marginal cost of abating greenhouse gas emissions, ... and would probably generate large transfers of wealth between countries" (McKibbin and Wilcoxen 2002, p.126); and (vi) "No individual government has an incentive to police the agreement...The Kyoto Protocol can only work if it includes an elaborate and expensive international mechanism for monitoring and enforcement" (McKibbin and Wilcoxen 2002, p.126).

Against this criticism, two central questions arise with respect to forthcoming climate policy negotiations. First, does the Kyoto Protocol really fall that short of basic economic principles?

\footnotetext{
${ }^{11}$ For example, Nordhaus and Boyer (1999, p.125) find that the Protocol does not "bear any relation to an economically oriented strategy that would balance the costs and benefits of GHG reductions."
} 
Second, are there fundamentally better approaches to climate policy and - if not - how could the Kyoto Protocol be amended towards a more practical and efficient strategy?

\section{(i) Is the Kyoto Protocol Totally Flawed?}

Economists are generally at unease if decision-making is not based on a comprehensive costbenefit analysis. Because of the huge uncertainties in the science of climate change, the targets and timetables underlying the Kyoto Protocol were not derived from a clear-cut costbenefit analysis, but rather emerged from a (partially ad-hoc) political process involving hard bargaining on the scope, timing and distribution of emission reduction. Negotiating countries revealed different perceptions on the urgency and scale of abatement by putting different weights to the relative severity, irreversibility and risks associated with action and inaction. After all, the final version of the Kyoto Protocol implies only moderate emission reduction and adjustment cost to the Parties (even with inclusion of the U.S) when accounting for "hot air", sink credits, and the use of flexible instruments. Thus, the agreement is in broader line with recommendations based on tentative numerical cost-benefit analysis conducted by opponents to the Protocol (suggesting only moderate reductions from BaU levels in the near future). Furthermore, it seems unfounded to accuse Kyoto of a total lack in the ultimate economic or environmental policy objective, pointing out that concrete policies beyond the first commitment period are missing. In qualitative terms, the Kyoto Protocol reflects scientific evidence from the IPCC on the need for long-term emission reduction. Reconciling diverging views of the Parties in the short-term seems like a wise strategy to get the political process on an IEA going at all. From a game-theoretical perspective, it may even be more efficient that Kyoto does not specify an aggregate target, since the latter exacerbates any freeriding incentives that may already exist (Barrett 1998, p.33).

Kyoto is doing less than perfect on the cost-efficient implementation of emission reduction targets which would require full "where"- and "when"-flexibility. However, in real policy practice, most economists were strongly in favor of the Protocol, since it constitutes the first international environmental agreement which seeks to achieve environmental targets using market-based instruments. With regard to "where"-flexibility, the Kyoto Protocol allows for the use of three flexible instruments, which are all ultimately based on the fundamental idea of tradable pollution rights: (i) international emissions trading (IET) between Annex B countries, (ii) joint implementation (JI) between Annex B countries, and (iii) the clean 
development mechanism (CDM) between Annex B countries and non-Annex B countries, i.e. developing countries. CDM explicitly extends "where"-flexibility to developing countries in order to exploit large potential for low-cost abatement.

In principle, use of the CDM implies that developing countries that have so far not adopted binding emission constraints become part of the abatement coalition. ${ }^{12}$ Signatory Annex B countries can reduce their abatement burdens by financing "project activities resulting in certified additional emission reductions" in developing countries (UNFCCC 1997, Article 12). In turn, this implies that developing countries are committed to business-as-usual emissions at the project level. As to "when"-flexibility, the Kyoto Protocol only allows for banking of permits. While the exclusion of borrowing entails some potential efficiency losses in theory, it can be seen as a hedging strategy to prevent strategic incentives for "postponing and doing nothing".

The issue of transfers between countries that are embodied in the initial allocation of emission rights is at the very heart of the equity debate. There is no generally accepted definition of equity. Equity principles refer to normative concepts of distributive justice or fairness that might be perceived as very different. ${ }^{13}$ The typical device for an economist is to separate efficiency from equity considerations and rely on (non-distortionary) lump-sum transfers in order to meet some exogenous equity criterion. However, efficiency and fairness are closely intertwined concerning the incentives of participation and compliance. The outcome of the Kyoto conference in December 1997 backs this proposition, though concepts of equity have remained rather vague during the negotiation process. Industrialized countries and economies in transition (both of them referred to as Annex B countries) have committed themselves to reducing GHG emissions to varying degrees, while the developing countries remain uncommitted, apparently meaning to reflect differences in the "ability to pay". Ultimately, the

\footnotetext{
${ }^{12}$ As noted by several analysts, the CDM may encounter severe problems of verification: not only do developing countries have incentives to offer projects that would have been undertaken anyway, but the Annex B countries also have incentives to select these projects if they can be acquired at lower cost (Barrett 1998).

${ }^{13}$ Ringius et al. (1998) distinguish five equity principles: Egalitarian, i.e. people have equal rights to use the atmosphere; horizontal, i.e. actors under similar (economic) conditions have similar emission rights and burden sharing responsibilities; vertical, i.e. the greater the capacity to act or ability to pay becomes, the greater the (economic) burden will be; polluter pays, i.e. the greater the contribution to the problem is, the greater the burden will be; and sovereignty, i.e. current emissions constitute a status quo right now.
} 
Kyoto Protocol provisions go back to the Berlin Mandate from 1995, when developing countries were not expected to limit their emissions. The Berlin Mandate reflected widespread consensus that countries "graduate" into a set of obligations commensurating with their abilities to pay.

Developing countries, although not committed to binding emission constraints, may well form part of the transfer system via CDM providing larger benefits both to developing as well as industrialized countries (see e.g. Böhringer et al. 2003 or Böhringer and Löschel 2003).

A frequent accusation about the Kyoto architecture is that the quantity-based approach is rather inefficient and doomed to excessive adjustment costs. As has been pointed out before, the appropriate policy for limiting GHG emissions - given the uncertainty on costs and benefits - is a mixed system in which a finite penalty provides an "escape valve" under a quantity regime in case abatement costs turn out to be very high. The actual setting of the Kyoto Protocol implies emission caps at very lax levels that could be tightened gradually over time in subsequent commitment periods. Thus, the risk of unacceptably high prices is relatively small. Larger price shocks and fluctuations could be dampened by permit banking, which is already foreseen in the Protocol. From a practical policy-making perspective, the quantity element under the Kyoto architecture offers the advantage of a transparent metric for burden-sharing negotiations. Furthermore - if applied at the global scale - it allows for a direct control of the environmental outcome.

Finally, we turn to the issue of sanctions for deterring free-riding and non-compliance. In the event of noncompliance to the Kyoto Protocol, the violator will be deducted 1.3 times the amount of the violation from its emission allowance for the next commitment period (possibly 2013-2017). The violator may also be barred from using the flexibility mechanism. When assessed more rigorously, the current Kyoto sanction mechanisms appear rather weak and ineffective: Application of the penalty needs consent of the violator to be in place. Furthermore, the sanction mechanism - applying to future control periods - provides freerider incentives, as the violator may insist on generous emission allocations. Finally, the exclusion from the emissions trading regime is not very efficient, as emissions trading typically implies a win-win-situation; hence, the punishers will be also hurt. In essence, the current Kyoto sanctions hardly seem renegotiation-proof (Finus 2003). 


\section{(ii) Giving Up or Amending Kyoto}

Since the beginning of the Kyoto process in 1997, numerous proposals on alternative architectures of global climate policy have been developed (see Aldy et al. 2003 for a recent cross-comparison of some proposals). They may be broadly divided in two categories: first, proposals that adopt direct price and quantity instruments or a combination of both, and second, proposals that support common R\&D efforts. Within the first category, proposals typically incorporate a price cap to limit the costs of GHG mitigation policies. The price cap may form part of a hybrid policy mix combining some cap-and-trade setting with a safetyvalve (e.g. Alday et al. 2001 or Jacoby and Ellerman 2003). Alternatively, the price cap may come as a harmonized carbon tax across regions forming part of the abatement regime (e.g. Cooper 1998, Pizer 1999, and Victor 2001). While the harmonized carbon tax approach bears some theoretical appeal, monitoring and enforcement will be extremely difficult. ${ }^{14}$ There are obviously strong incentives for countries to offset emission taxes with less visible compensatory policies or to miscount initial energy taxes and subsidies. ${ }^{15}$ Another major problem of the harmonized carbon tax approach is that there are implicit asymmetric impacts across countries. An explicit compensation scheme with side payments would have to be negotiated, which might be even more controversial than the international debate on alternative emission entitlement rules or abatement duties. ${ }^{16}$ The second category of proposals (e.g. Barrett 2001, 2003 and in part Benedick 2001) puts emphasis on the inherent difficulties in enforcing participation and compliance to the provision of global public goods. These proposals depart from emission commitments as well as market-based instruments and instead build on cooperative climate-friendly R\&D protocols and common technology standards as an implicit self-enforcing strategy for emission mitigation. However, such an approach reveals severe shortcomings with respect to environmental effectiveness and economic efficiency. There are severe problems of windfall-gains with respect to R\&D subsidies as incentives to free-ride on R\&D spillovers.

\footnotetext{
${ }^{14}$ Nordhaus (2001) provides a list of additional, rather ad-hoc, arguments for harmonized carbon taxes, such as higher transparency, less susceptibility to corruption, and preserved national sovereignty.

${ }^{15}$ In this context, Victor $(2001$, p. 86) warns of a "goulash of prior distortions, new taxes, and political patches."

${ }^{16}$ One proposal to avoid asymmetries is to implement an international tax with an international environmental agency that balances asymmetries via the reallocation of tax revenues (Bradford 2002).
} 
Overall, it appears that alternative proposals to the basic architecture of the Kyoto Protocol will not necessarily do better with respect to key criteria for global climate policy, such as environmental effectiveness, efficiency, equity, or enforcement. Given that the basic Kyoto architecture provides substantial flexibility, it seems reasonable to think about ways that the actual implementation can be amended towards a more effective and efficient structure. After all, the Kyoto process has achieved - with considerable efforts - broader voluntary international agreement that, for the first time, strongly pursues a market-based approach.

What would major amendments look like?

First, it is inevitable that the developing world is gradually becoming involved. The developing countries account for a large and growing share of emissions. Thus, in the midrun, climate protection cannot be successful without substantial participation by the developing countries. Assignment of emission entitlements to lock developing countries into the abatement coalition will inevitably involve controversial equity debates. ${ }^{17}$ To relax these debates, the short-term objective of broadening participation should not be so much to redistribute costs from the industrialized to the developing world as to lower the overall abatement bill. $^{18}$

Second, the actual provisions for sanctioning violators must be improved. One proposal is that violating sellers transfer revenues to some fund, while violating buyers pay a mark-up to the fund. The fund then can be used to compensate other signatories. Another option for sanction is to follow suit according to the principle of reciprocity and reduce abatement efforts (Finus 2003). Furthermore, diligent linkage to trade or R\&D agreements may promote participation and compliance to the Kyoto Protocol (Barrett 2003).

Third, during the initial commitment periods, Kyoto could be endowed with a safety valve (see Roberts and Spence 1976, McKibbin and Wilcoxen 2002, Kopp et al. 1997, Victor 2001, Jacoby and Ellermann 2002) to hedge against uncertainty and volatility of permit prices. Under the safety valve, the national authorities can sell permits in unlimited amounts at a pre-

\footnotetext{
${ }^{17}$ Note that an earlier draft of the Protocol allowed developing countries to choose, at any time and on a voluntary basis, a level of emission control that was appropriate to their circumstances.

${ }^{18}$ A more comprehensive emissions trading system would also reduce concerns on counter-productive leakage through relocation of emissions to non-participating countries.
} 
set price. This would provide an upper limit to the marginal cost of the emission cap. Effectively, the per-unit penalty under the Kyoto Protocol constitutes a safety valve. If the penalty or, for that matter the safety valve, is set far below the expected marginal cost at the level of the cap, it would relax the target emissions reduction and effectively change the control instrument from quantity to price. ${ }^{19}$

However, as put forward by Ellerman and Jacoby (2003), the safety valve is not desirable as a long-term feature of cap-and-trade system, because it involves complex coordination of price and quantity instruments. Finally, assuming it will prove no easier to co-ordinate a global safety valve than it has been to decide on a global carbon tax, the phasing-out of any safety valves in national programs will require the creation of a well-functioning market in emissions permits. Once the cap-and-trade system is in place, similar results can be achieved by banking.

\section{Conclusions}

More than 10 years of climate policy negotiations have produced the Kyoto Protocol, the first legally binding international agreement on climate protection, which may enter into force in the near future. Given the large uncertainties in the science of climate change and the fundamental incentive problems of sovereign states, it is clear that a perfect (first-/secondbest) climate policy can not be achieved in practice. The Kyoto Protocol is thus necessarily only one out of many possible imperfect architectures to address the risks posed by global climate change.

Opponents to the Protocol have condemned it as a "deeply flawed agreement that manages to be both economically inefficient and politically impractical" (McKibbin and Wilcoxen 2002, p.107). This article sustains a more positive perspective on the Kyoto architecture. Key elements of the Protocol comply with basic economic principles. The Protocol is based on a control mechanism that allows iterative adjustment and movement toward evolving goals. A system of periodically negotiated five-year periods supports a flexible approach that allows policy-makers to adjust their decisions according to better information obtained in the future.

\footnotetext{
${ }^{19}$ In the extreme - if the price is low enough to be triggered frequently - this will lead to a globally harmonized carbon tax.
} 
The Protocol constitutes the first international environmental agreement that builds on market based instruments to determine cost-efficient responses to the undisputed need for GHG abatement. After tough bargaining, Kyoto came up with a burden-sharing scheme for the first commitment period that all major Parties (with exception of the US) have accepted as a "fair" compromise, hereby reflecting historic responsibilities for the GHG externality as well as ability to pay. On the other hand, it must be clearly stated that the Kyoto Protocol - as it stands now - has not achieved a decisive breakthrough in international climate policy. In the first place, sink credits, hot air through emissions trading and, in particular, U.S. repudiation will make Kyoto ineffective in environmental terms during the first commitment period. Second, it has yet to be negotiated what must be done after the first commitment period.

The apparent "failure" of the Kyoto Protocol with respect to environmental effectiveness does not come so much as a surprise given the huge incentive problems of providing a global public good. Ironically, in the concrete case, it may be more of an advantage than a disadvantage that Kyoto, which originally attempted large early emission reductions (with potentially large costs for some nations), has been converted to a gradual-start agreement with very low costs. The reasons are that (i) this lowers concerns on the disadvantages of a too rigid quantity-based approach, (ii) it appeases opponents who insist that Kyoto has been way too ambitious in short-term emission reductions, and (iii) it increases the chance that the U.S. might rejoin the Protocol under the new conditions. Compliance costs to the U.S. economy seem rather moderate, which could enhance domestic U.S. political pressure in favor of coordinated international abatement.

Thus, even without any effective emission reductions in the first commitment period, the ratification of Kyoto is crucial for the further policy process of climate protection. It has established a broad-based international mechanism that provides a valuable starting point for efficient climate policies in the future.

Given the shared belief that substantial global emission reduction is required in the long run, the major challenge remains as to how we can push institutional settings that promote comprehensive international cooperation. In the first place, this requires incentives for developing countries to participate. Ultimately, this comes down to how abatement duties - or emission entitlements - should be allocated across countries over a longer time horizon. This issue has already dominated previous climate negotiations and proved extremely difficult to 
solve, even though the overall abatement targets under discussion were very moderate in comparison with the long-term requirements suggested by the IPCC. Consequently, some pragmatic reconciliation of the equity-efficiency divide must be at the top of the research and policy agenda. In the second place, a credible system of direct or indirect sanctions must be developed that can deter free-riding. Applied research should be dedicated to the question of which sanction mechanisms are likely to provide concrete improvements in practice.

A final caveat should be made: Kyoto, as it stands now, has emerged from tedious bargaining. In this paper, both the indicated perspective of amendments as well as possible alternatives are discussed from a theoretical point of view. One can hardly predict how the theoretical proposals will materialize in practice after passing the negotiation process.

\section{References}

Alday, J.E. , Orszag, P.R. and J.E. Stiglitz (2001), 'Climate Change: An Agenda for Global Collective Action', paper prepared for the conference on The Timing of Climate Change Policies, Pew Center on Global Climate Change, Washington, D.C., October 2001.

- Aldy, J.E., Barrett, .S, and Stavins, R.N. (2003), 'ThirteenPlusOne: A Comparison of Global Climate Policy Architectures', working paper, John F. Kennedy School of Government (CBG), Harvard University.

Arrow, K,J., Fisher A.C. (1974), 'Environmental Preservation, Uncertainty, and Irreversibility', Quarterly Journal of Economics, 88, 312-319.

Bohm, P., Larsen, B. (1994), 'Fairness in a Tradable Permit Treaty for Carbon Emissions Reductions in Europe and the former Soviet Union', Environmental and Resource Economics, 4, 219-239.

Barrett, S. (1994), 'Self-Enforcing International Environmental Agreements', Oxford Economic Papers, 46, 804-878.

- (1997), 'Heterogeneous International Environmental Agreements", in: C. Carraro, ed., International Environmental Negotiations: Strategic Policy Issues , Edward Elgar, Cheltenham, 9-25.

- (1998), 'Political Economy of the Kyoto Protocol', Oxford Review of Economic Policy, 14 (4), 20-39. 
- (2001), 'Towards a Better Climate Treaty', World Economics, 3(2), 35-45.

- (2003), Environment and Statecraft, Oxford University Press, Oxford.

Botteon, M. and C. Carraro (1997), 'Burden Sharing and Coalition Stability in Environmental Negotiations with Asymmetric Countries', in: C. Carraro (ed.), International Environmental Negotiations: Strategic Policy Issues, Edward Elgar, Cheltenham, 2655.

Böhringer, C. (2002), 'From Kyoto to Bonn: From Little to Nothing?', The Energy Journal, 23(2), 51-71.

- Helm, C. (2001), 'On the Fair Division of Greenhouse Gas Abatement Cost', ZEW Discussion Paper No. 01-67, Mannheim.

- Conrad, K. and A. Löschel (2003), 'Carbon Taxes and Joint Implementation: An Applied General Equilibrium Analysis for Germany and India', Environmental and Resource Economics 24 (1), 49-76, 2003

- Löschel, A. (2003), 'Risk in Project-Based Emission Trading', ZEW Discussion Paper No. 02-68, Mannheim.

- Vogt, C. (2003a), 'Economic and Environmental Impacts of the Kyoto Protocol', Canadian Journal of Economics, 36 (2), 475-494.

- Vogt, C. (2003b), 'The Dismantling of a Breakthrough: The Kyoto Protocol Just Symbolic Policy', European Journal of Political Economy, forthcoming.

Bradford, D.F. (2002), 'Improving on Kyoto: Greenhouse Gas Control as the Purchase of a Global Public Good', working paper, Princeton University.

Buchner, B., Carraro, C. and I. Cersosimo (2002), 'Economic consequences of the US withdrawal from the Kyoto/Bonn Protocol', Climate Policy, 2 (4), 273-292.

Carraro, C. and D. Siniscalco (1993), 'Strategies for the International Protection of the Environment', Journal of Public Economics, 52, 309-328.

(1998), 'International Environmental Agreements: Incentives and Political Economy', European Economic Review, 42, 561-572.

Congleton, R.D. (1992), 'Political Institutions and Pollution Control', Review of Economics and Statistics, 74 (3), 412-421.

- (2001), 'Governing the Global Environmental Commons: The Political Economy of International Environmental Treaties and Institutions', in: Schulze G.G., Ursprung H.W., (eds.): International Environmental Economics, Oxford University Press, Oxford, 241-263. 
Cooper, R. (1998), 'Towards a Real Treaty on Global Warming', Foreign Affairs, 77(2), 6679.

Dixit, A. and R. Pindyck (1994), 'Investment Under Uncertainty’, Princeton University Press, New York.

Finus, M. (2003), 'International Cooperation to Resolve International Pollution Problems', in Cogoy, M. and K. Steininger (eds.), Economics of Sustainable Development: International Perspectives, EOLSS, The Encyclopedia of Life Support Systems, ch. 1.21.4.3., forthcoming.

Finus, M. and S. Tjøtta (2002), 'The Oslo Protocol on Sulfur Reduction: The Great Leap Forward?', Journal of Public Economics, forthcoming.

Gollier, C., Jullien, B., and N. Treich (2000), 'Scientific progress and irreversibility: an economic interpretation of the Precautionary Principle', Journal of Public Economics, $75,229-253$.

Ha-Duong, M., Grubb, M., and J. C. Hourcade (1997), 'Influence of socioeconomic inertia and uncertainty on optimal $\mathrm{CO}_{2}$-emission abatement', Nature, 390, 270-273.

Hanemann, W.M. (1989), 'Information and the Concept of Option Value', Journal of Environmental Economics and Management 16(1), 23-37.

Higgins, P.A.T., Mastrandrea, M.D., and S.H. Schneider (2002), 'Dynamics of climate and ecosystem coupling: abrupt changes and multiple equilibria', Philosophical transactions of the Royal Society of London Series B - Biological Sciences, 357 (1421), 647-655, London.

IEO (2001), 'International Energy Outlook 2001', U.S. Department of Energy, Energy Information Administration, http://www.eia.doe.gov.

IPCC (2001), 'Climate Change 2001: Mitigation', Working Group III, Third Assessment Report, Section 1.3.1, Cambridge University Press, Cambridge.

Jacoby, H.D. and A.D. Ellermann (2002), 'The 'Safety Valve' and Climate Policy', Energy Policy, forthcoming.

Kopp, R., Morgenstern, R., and W. Pizer (1997), 'Something for Everyone: A Climate Policy That Both Environmentalists and Industry Can Live With', Policy Brief, Resources for the Future, Washington D.C.

McKibbin, W.J. and P.J. Wilcoxen (2002), 'The Role of Economics in Climate Change Policy', Journal of Economic Perspectives 16(2), 107-129.

Mishan, E. J. (1975), ‘Cost-Benefit Analysis', Allen \& Unwin, London. 
Morrisette, P. and A. Plantinga (1991), 'The Global Warming Issue: Viewpoints of Different Countries', Resources, 103, 2-6.

Moulin, H. (1990), 'Fair division under joint ownership', Social Choice and Welfare, 7, 149170.

Moulin, H. (1991), 'Welfare bounds in the fair division problem', Journal of Economic Theory, 54 (2), 321-337.

Murdoch, J.C. and T. Sandler, T. (1997a), 'The Voluntary Provision of a Pure Public Good: The Case of Reduced CFCs Emissions and the Montreal Protocol', Journal of Public Economics, 63, 331-349.

(1997b), 'Voluntary Cutbacks and Pretreaty Behavior: The Helsinki Protocol and Sulfur Emissions', Public Finance Review, 25, 139-162.

Nemry, F., 2001 'LULUCF39 v4 - Quantitative implications of the decision CP.7 on LULUCF.' Personal Communication.

Nordhaus, W.D. (2001), 'After Kyoto: Alternative Mechanisms to Control Global Warming', Presentation at the $20^{\text {th }}$ Anniversary Meeting of the International Energy Workshop, IIASA, Laxenburg, Austria.

Nordhaus, W.D., and J.G. Boyer (1999, 'Requiem for Kyoto: An Economic Analysis', Energy Journal, Special Issue, 93-130.

Pearce, D. (1998), 'Cost-Benefit Analysis and Environmental Policy', Oxford Review of Economic Policies, 14 (4), 84-100.

Pizer, W. (1999), 'The Optimal Choice of Climate Change Policy in the Presence of Uncertainty', Resource and Energy Economics, 21, 255-287.

Ringius, L., Torvanger, A. and B. Holtsmark (1998), 'Can multi-criteria rules fairly distribute climate burdens? OECD results from three burden sharing rules', Energy Policy, 26 (10), 777-793.

Roberts, M.J. and M. Spence (1976), 'Effluent Charges and Licenses under Uncertainty', Journal of Public Economics', 5, 193-208.

Rose, A., B. Stevens, J. Edmonds, and M. Wise (1998), 'International equity and differentiation in global warming policy', Environmental \& Resource Economics, 12, $25-51$.

Springer U. (2002), 'The market for tradeable GHG permits under the Kyoto Protocol: a survey of model studies', Energy Economics, 25 (5), 527-551.

UNFCCC (1992), 'United Nations Framework Convention on Climate Change', New York, 9 May 1992, in force 21 March 1994, 31 ILM 849. 
- (1997), 'Kyoto Protocol to the United Nations Framework Convention on Climate Change', FCCC/CP/L.7/Add.1, Kyoto.

Victor, D. (2001), 'The Collapse of the Kyoto Protocol and the Struggle to Slow Global Warming,' Princeton University Press, Princeton.

Weitzman, M.L. (1974), 'Prices vs. Quantities', Review of Economic Studies, 41 (4), 477-491.

Wigley, T.M.L., Richels, R.. and J.A. Edmonds (1996), 'Economic and Environmental Choices in the Stabilization of Atmospheric $\mathrm{CO}_{2}$ Concentrations', Nature, 379, 240243. 